\title{
Creating Human Beings
}

\section{I0.I Introduction}

It is a momentous thing to bring a new human being into the world. Conception, pregnancy, childbirth, and parenting are all loaded with cultural significance and are the source of a great deal of the value people find in their lives. They inspire joy, anxiety, disagreement, and debate like few other topics. They also implicate medicine and ethics.

We begin our discussion in this chapter by examining whether there is a right to procreate. We derive a negative right to procreative autonomy from the rights of autonomous agents to control their own bodies. Like other autonomy rights, these rights are limited in scope by potential negative effects on others. Nevertheless, this right would permit the use of a wide range of procreative technologies. A positive right to procreative autonomy would constitute a claim to assistance with procreation. We argue that people's interests in procreating may ground claims to assistance on the basis of justice, but they have no special weight compared with other interests and so do not qualify as positive rights.

From procreative autonomy we turn to the ethics of making decisions that affect which humans come into being (or come to term). These divide into two categories: fixed-identity and identity-determining decisions. Fixedidentity decisions occur when someone chooses whether or not to bring a specific individual into the world. For example, a decision to terminate a pregnancy in the first trimester because the fetus has Down syndrome is a decision not to allow a specific fetus to develop and be born. The most fundamental question in fixed-identity cases is whether and when abortion is ethically permissible. Many other important bioethical questions concerning fetuses cannot be answered until the answer to that question is settled. We argue that pre-sentient fetuses are not harmed by death and so it is not wrongful for someone to exercise their right to control their body and terminate a pregnancy. Once sentience emerges - which is probably no 
earlier than twenty-eight weeks gestational age - it is plausible that death harms the fetus. However, due to the fetus's weak psychological connections to its possible future, the harm of death is relatively small. Terminating even a late-stage pregnancy can therefore be justified when there is a morally important reason to do so.

Identity-determining decisions occur when someone's choice affects which of several possible individuals will come into existence. For example, a couple might attempt to get pregnant now or - concerned about an outbreak of an infectious disease that might damage a fetus - wait until the end of the summer. The sperm and egg that would be part of conception now will not be the same sperm and egg that would be involved in a conception a few months hence. The decision of whether or not to delay determines which of two possible individuals will later exist. Identity-determining cases are difficult when the individuals who could come to exist differ substantially in their expected quality of life or well-being. Many philosophers judge that it would be wrong to bring into existence someone whose life would go worse than that of another individual who could be brought into existence instead. But it is hard to make sense of this judgment once we note that there is no one whose actual life is made worse. We argue that in at least a subset of these "nonidentity" cases, it is not wrong to cause the existence of someone whose life will go worse than that of another possible individual.

Finally, we apply our theoretical conclusions regarding fixed-identity and identity-determining decisions to two practical issues: the use of medical technologies to select the sex of one's child and public health measures in the context of a Zika virus outbreak.

The discussion here, as elsewhere in the book, is selective. We omit important strands of argument, such as alternative defenses of the permissibility of abortion. We also omit some cutting-edge topics in bioethics that relate to procreation, such as enhancement and gene editing (although Chapter 9 takes up aspects of these two topics). Perhaps more significantly, this chapter engages population ethics: the ethics of making decisions that affect who will come into existence and how many individuals will come into existence. The boundaries of population ethics do not end with the human species. Our actions affect which nonhuman animals exist, too, such as via our food choices or habitat destruction. Though we think these issues are tremendously important, we set them aside here for lack of space. ${ }^{\mathrm{I}}$

${ }^{\mathrm{I}}$ For some recent discussion, see Sue Donaldson and Will Kymlicka, Zoopolis (New York: Oxford University Press, 20II); and Lori Gruen, Ethics and Animals (New York: Cambridge University Press, 20II), chap. 6. 


\section{I0.2 Procreative Autonomy}

Control over whether and how one creates new human beings is immensely important to almost everyone. Those who wish to have sexual relationships without procreating need ready access to contraception. Those who wish to procreate and parent may need assistance in conceiving, bearing, and rearing a child. Do all these people have a right to access what they need? We argue here that persons have a negative right to procreative autonomy, that their interests in procreation do not ground any special claim to assistance, but the value of parenting may support assistance in being parents. ${ }^{2}$

\section{The Right to Procreative Autonomy}

As we discussed in Chapter 3, rights typically function to protect important interests. But to justify saying that some person $\mathrm{P}$ has a right to $\mathrm{X}$, it is not sufficient to show that she has an important interest in X. It is also necessary to show that a right is necessary to protect $\mathrm{P}$ 's interest in $\mathrm{X}$ and that it is $P$ 's interest in X that merits protection (rather than, say, someone else's equally strong interest in X). ${ }^{3}$ Thus, the existence of a right to procreative autonomy does not simply follow from the important interests such a right would support.

Start with the question of whether there is a negative right to procreative autonomy. Such a right would consist in a claim against others not to interfere with a person's procreative actions. We think that a prima facie negative right to procreative autonomy is entailed by other rights that autonomous agents have. ${ }^{4}$ In particular, autonomous agents have a right to bodily integrity, which gives a person the right to control what happens to their body. ${ }^{5}$ This right includes the power to consent to sex with another autonomous individual. In typical cases it would be wrongful for others to

\footnotetext{
2 Similar ideas to those we discuss under the label of "procreative autonomy" are discussed by others under the labels of "reproductive liberty," a "right to procreate," and "procreative liberty." See, respectively, John Harris, "Reproductive Liberty, Disease, and Disability," Reproductive Biomedicine Online ro (2005): I3-I6; Sarah Conly, "The Right to Procreation: Merits and Limits," American Philosophical Quarterly 42 (2005): I05-I I 5; and John Robertson, Children of Choice (Princeton, NJ: Princeton University Press, I996). We are not drawing fine distinctions among these terms.

3 These conditions correspond to the existence and entitlement theories underlying a putative right. See Joseph Millum, The Moral Foundations of Parenthood (New York: Oxford University Press, 2018), I6-I7.

4 This chapter does not consider the issue of procreative acts by nonautonomous individuals.

5 See Chapter 5 .
} 
interfere with their having sex. The right also includes the right to refuse medical interventions or other bodily intrusions. So, if sex leads to pregnancy, the pregnant individual has the right to carry the pregnancy to term without interference by others. Thus, in paradigmatic cases of procreation, the acts involved fall clearly within the scope of the broader right to bodily integrity.

What about assisted reproduction where medical professionals are involved in helping an individual to become pregnant, such as through fertility-enhancing drugs or in vitro fertilization (IVF)? These methods comprise medical procedures that autonomous individuals are also generally thought to have the power to consent to or refuse. There is nothing different in kind about the medical procedures involved in assisted reproduction than the procedures involved in other medical care that also require consent.

The negative right to procreative autonomy as we have derived it is prima facie because its scope is restricted in the same way as with other autonomy rights: it does not extend to actions that wrong others, including by violating their rights against being harmed. It follows that questions of who, if anyone, is wronged by procreative acts are crucial to determining whether there are any grounds for restricting them. When considering whether an individual should be permitted to use some novel means of procreating, those who would restrict access must first show that there is a victim.

Deriving a negative right to procreative autonomy from widely accepted autonomy rights has important implications for debates about assisted reproductive technology (ART). It implies, for example, that people should be free to make use of fertility-enhancing drugs, IVF, and the like. Moreover, these results follow without our having to endorse anything special about procreation per se. ${ }^{6}$

The question of whether there is something particularly important about procreating is, however, relevant to assessing claims for a positive right to assistance with procreation. Understood as just one way that someone can exercise their bodily autonomy, there is no reason to provide them with additional resources in order to procreate. But, for example, a couple who is struggling to conceive may not be able to afford IVF

${ }^{6}$ Other arguments for a liberty right to access ART generally involve a great deal of argument intended to establish the importance of procreation. See, e.g., John Robertson, "Liberalism and the Limits of Procreative Liberty: A Response to My Critics," Washington \& Lee Law Review 52 (1995): 233-267, at 235 . 
themselves. Should the state subsidize the treatment? Likewise, there are infertile couples who cannot conceive even with existing medical technology. Should government research agencies support research into infertility in the same way as they might support research into dengue fever or lung cancer?

A number of writers have argued that procreation is special. One possibility is that there is something especially valuable in the genetic or biological connection between a parent and the child created by them. Certainly, many people seem to think that genetic relationships are important. However, efforts to justify such views have not been persuasive. ${ }^{7}$ The desire to make a child that resembles me - in looks or personality - seems too trivial, if not narcissistic. The desires to pass on my genes or continue my lineage likewise seem to put an implausible degree of weight on the importance of genetic connections. ${ }^{8}$ Given the value of persons, there is surely something very morally weighty involved in bringing a person into existence. But whether the act of procreation has positive value presumably then depends on the fate of the person so created. Consequently, many writers are skeptical that humans have a strong interest in genetic or biological reproduction in itself. Instead, it is argued, procreation and gestation are "valuable largely because of the opportunity it gives people to parent a child (i.e., to be 'rearers')." "We endorse this view.

The final possible ground for a positive claim to assistance with procreation, then, is that people have an interest in becoming parents, where this is understood as a social relationship between parents and their children. For many people, parenting is a central life project and a source of a great deal of meaning. Through it they create and maintain a family while assisting a child through their development. ${ }^{\text {Io }}$ The intimate relationship that (good) parents have with their children is both valuable and unique. ${ }^{\text {II }}$ For some individuals, then, it is plausible that their lives would go much

7 See Tina Rulli, "Preferring a Genetically-Related Child," Journal of Moral Philosophy I 3 (2016): $669-698$, for an overview of various grounds for preferring a genetically related child and arguments against them in the context of a duty to adopt rather than procreate. Rulli allows a possible exception for those who powerfully desire to experience pregnancy.

${ }^{8}$ For reasons to distrust our intuitions about the importance of genetic connections, see Joseph Millum, "How Do We Acquire Parental Rights?," Social Theory and Practice 36 (2010): I I 2-I 32 , at $\mathrm{I} 25-\mathrm{I} 28$.

9 Andrew Botterell and Carolyn McLeod, "Can a Right to Reproduce Justify the Status Quo on Parental Licensing?,” in Sarah Hannan, Samantha Brennan, and Richard Vernon (eds.), Permissible Progeny (New York: Oxford University Press, 201 5), I 84-207.

Io Millum, Moral Foundations of Parenthood, 50-53.

I I Harry Brighouse and Adam Swift, "Parents' Rights and the Value of the Family," Ethics I I7 (2006): 80-108. 
worse if they were unable to parent. Such powerful interests in parenting could ground correspondingly powerful claims to assistance with becoming parents, such as through subsidizing access to ART.

To this proposal it might be objected that one need not procreate in order to parent. Adoptive parents are just as much parents of their children, and rearing a genetically unrelated child is no less valuable than rearing one's offspring. ${ }^{12}$ In a large number of countries, there are many children in need of parenting. For example, the US Department of Health and Human Services reported 437,000 children in the foster care system in 2016, of whom I 8 ,000 were waiting to be adopted. ${ }^{13}$ These children in foster care are in need of loving, stable families and would benefit enormously from adoption. Crucially, they already exist. The children who might be created through ART, on the other hand, do not yet exist and their needs will matter morally only if they do come to exist. Consequently, given a choice between creating a new child (whether through ART or a more traditional method) and parenting a child who already exists and needs a stable family, some philosophers think we have an ethical obligation to choose the latter. ${ }^{\mathrm{I}}$

Were there a surplus of healthy babies in need of adoption, we think this argument would be compelling. However, matters on the ground are more complicated. For the most part, the children in foster care waiting to be adopted are not infants. For example, in the United States the average age of children waiting to be adopted is 7.7 years, and only 4 percent are under one year of age. Though children who are adopted later do generally recover to a large extent from the negative effects of early deprivation, they are still less likely to form secure attachment relationships with their new parents. ${ }^{\text {IS }}$ Moreover, many of these children are medically complicated

${ }^{12}$ There might be differences in specific ways in which parenting an adopted child is valuable for the parents (Tina Rulli, "The Unique Value of Adoption," in Francoise Baylis and Carolyn McLeod [eds.], Family-Making [Oxford: Oxford University Press, 2014]).

${ }^{13}$ US Department of Health and Human Services, Administration for Children and Families, The AFCARS Report (2017) (available at www.acf.hhs.gov/sites/default/files/cb/afcarsreport24.pdf). Statistics Canada reports 28,030 foster children under fourteen years (Statistics Canada, Portrait of Children's Family Life in Canada in 20I6; available at wwwi 2.statcan.gc.ca/census-recensement/ index-eng.cfm). The UK Department of Education reports 72,670 "looked-after" children in England in 2017, of whom only 4,350 were adopted (www.gov.uk/government/collections/ statistics-looked-after-children).

${ }^{14}$ See, e.g., Daniel Friedrich, "A Duty to Adopt?," Journal of Applied Philosophy 30 (2013): 25-39.

is See Linda Van den Dries et al., "Fostering Security? A Meta-analysis of Attachment in Adopted Children," Children and Youth Services Review 3 I (2009): 4I IO-42 I; and M. H. Van Ijzendoorn and F. Juffer, "Adoption as Intervention: Meta-analytic Evidence for Massive Catch-up and Plasticity in Physical, Socio-emotional, and Cognitive Development," Journal of Child Psychology and Psychiatry 47 (2006): I228-I 245. According to van Ijzendoorn and Juffer the evidence does not suggest 
and so will require greater care than healthy children would. Adopting from foster care generally means missing out on one's child's early years, and parenting such a child is likely to be harder than average. We therefore think that it is not ethically required that prospective parents adopt such children, rather than procreate, even if it would be better to do so.

Meanwhile, private domestic adoptions and international adoptions are more likely to involve a healthy infant. However, domestic supply is exceeded by the number of parents looking to adopt, and children adopted from developing countries are frequently not those in great need of new families. ${ }^{16}$ Thus, other prospective adoptees - the healthy infants that many would-be parents ideally want - are likely to find parents in any case. There is therefore no duty to adopt them rather than procreate either.

Two caveats are in order here regarding our conclusions. First, while we believe that many individuals have a morally important interest in procreating in order to parent, this conclusion depends on the nonideal circumstances that prevail in the high-income countries with which we are familiar. In the United States and United Kingdom, for example, more just and efficient systems for finding permanent families for foster children might involve placing children for adoption at younger ages. So, it might currently be supererogatory for individuals to adopt instead of procreating, but it does not follow that government entities are off the hook. Given how important it is for a child to have a stable family environment, governments should do everything they can to find good parents for needy children, including providing incentives to possible adopters.

Second, the conclusions we have drawn so far regarding a right to procreative autonomy require the assumption that it is permissible to procreate in the first place. Though it is commonly thought that creating children is ethically permissible, even praiseworthy, this view has been challenged. One challenge is based on environmental degradation. More children means more consumption, which will accelerate climate change

substantial differences between adopted and nonadopted (birth family) peers in behavioral problems, even for children adopted older than one year.

I6 Data on the number of US couples looking to adopt are hard to obtain, but it apparently exceeds the number of babies given up for adoption at birth (see, e.g., Jeff Katz, "Adoption's Numbers Mystery," Washington Post, November 8, 2008; available at www.washingtonpost.com/wp-dyn/ content/article/2008/I I/07/AR2008II0702807.html). For a popular exposé of the international adoption industry, see E. J. Graff, “The Lie We Love,” Foreign Policy, October 6, 2009 (available at http://foreignpolicy.com/2009/Io/06/the-lie-we-love/). It may well be that many children in poorer countries would benefit enormously from adoption, but it does not follow that those children can be readily identified by foreign would-be adopters. 
and other effects of the overuse of the earth's resources. ${ }^{17}$ Another is based on the interests of the people who would be brought into existence. For example, David Benatar thinks that it is wrongful to bring people into existence because of the suffering that they will predictably undergo without having had any say in the matter of coming into existence. ${ }^{\mathrm{I}}{ }^{8}$

\section{Procreative Autonomy and Public Policy}

We have argued that individuals have a negative autonomy right to procreate derived from other autonomy rights they have to control their own bodies. This establishes a right against interference with attempts to procreate, including attempts that involve the help of (consenting) others. The desire to procreate does not, we have argued, have special weight, even though people may have a strong interest in parenting that grounds claims to assistance on the basis of distributive justice. What do these points of theory tell us about public policy concerning reproduction?

First, the right against interference with procreative acts implies a presumption in favor of allowing people to avail themselves of assistance with procreation. The burden of justification falls on those who would ban some practice or technology, not on those who want to use it. Even when evidence is provided that some form of assisted procreation is harming or otherwise wronging others, it does not follow automatically that it should be prohibited. Regulation that protects potential victims but still allows others as much freedom as possible should be attempted first. For example, a woman may act as a surrogate by agreeing to become pregnant on another's behalf. This may involve artificial insemination of the surrogate or IVF. The legality of paying surrogates for their services and the enforceability of surrogacy contracts varies by jurisdiction. Some critics argue that commercial surrogacy contracts are exploitative. This would be the sort of consideration that could count against the presumption of allowing people to procreate via surrogate mothers. But even if it were shown that commercial surrogacy contracts are often exploitative, it would be better to regulate them to prevent exploitative terms than to ban the practice outright. ${ }^{19}$ Later in this chapter, we examine sex selection in some detail.

${ }^{17}$ Thomas Young, "Overconsumption and Procreation: Are They Morally Equivalent?," Journal of Applied Philosophy (2001): I83-192.

18 David Benatar and David Wasserman, Debating Procreation (New York: Oxford University Press, 2015).

I9 For critical discussion, see Stephen Wilkinson, "The Exploitation Argument against Commercial Surrogacy," Bioethics I7 (2003): I69-187. 
This is another practice that some commentators have argued should be prohibited on the basis of anticipated social costs. ${ }^{20}$

Second, the bioethics literature, understandably, focuses more on questions relating to novel procreative practices and technologies than on ones whose permissibility is settled. Reproductive cloning and three-parent babies are much more exciting and controversial than whether people should have access to condoms. But emphasis on the ethics of novel means of exercising procreative autonomy might give the impression that these are the most important issues for public policy. We think this is typically mistaken. Many more people are affected - and affected more negatively - by the failure of states to protect aspects of their reproductive autonomy that are mostly uncontested by ethicists. For example, in 2017 an estimated I42 million women worldwide who were married or in a union had an unmet need for family planning. ${ }^{2 \mathrm{I}}$ Most women in low-income countries have not heard of emergency contraception, and providers frequently have negative attitudes toward it, even where emergency contraceptive products are available. ${ }^{22}$ Gender power disparities mean that many women and girls are not able to control the circumstances under which they have sexual relations, exposing them to unwanted pregnancies and infectious disease. ${ }^{23}$ When thinking about how state resources should be allocated to protect people's autonomy rights, these are the rights in greatest need of protection. ${ }^{24}$

${ }^{20}$ Some writers have argued that procreation itself typically burdens society so people should not be subsidized in procreating and parenting - doing so is like subsidizing an expensive hobby (see, e.g., R. S. Taylor, "Children as Projects and Persons: A Liberal Antinomy," Social Theory and Practice 35 [2009]: 555-576). However, procreation may also be providing benefits to other members of society. After all, we rely on the next generation to work to produce the goods that everyone will consume (S. Olsaretti, "Children as Public Goods?," Philosophy and Public Affairs 4I [2013]: 226-258). Whether adding an additional individual to the population is a net gain or a net cost will be very dependent on details of the social context, including a society's economy and what other potential procreators will do.

${ }^{21}$ United Nations, Department of Economic and Social Affairs, Population Division (2017), World Family Planning 2017 - Highlights (ST/ESA/SER.A/4I4).

22 Elizabeth Westley et al., "A Review of Global Access to Emergency Contraception," International Journal of Gynecology \& Obstetrics I 23 (2013): 4-6.

${ }^{23}$ Geeta Rao Gupta, “How Men's Power over Women Fuels the HIV Epidemic: It Limits Women's Ability to Control Sexual Interactions," British Medical Journal 324 (2002): I83-184.

${ }^{24}$ It is sometimes thought that resource allocation issues are irrelevant to negative rights because they only impose duties on others not to interfere. This is mistaken. In order for negative rights including rights to bodily integrity and procreative autonomy - to be meaningful, they must be protected. To protect such rights effectively requires enforcement by the state. For example, an individual's right to bodily integrity will be effective only if there are laws against assault, and police and courts who enforce those laws. But to protect rights requires resources; for example, police must be paid and legal processes must be accessible and efficient. For extensive argument for and illustration of this point, see Henry Shue, Basic Rights (Princeton, NJ: Princeton University Press, 1996). 
Similar points apply to the positive claim to assistance with becoming a parent. We accept that this interest is morally weighty, such that it matters from the point of view of distributive justice. But in thinking about, for example, whether the state should subsidize IVF for infertile couples, we must consider what other claims there are to the resources that IVF requires. For many women around the world, access to complex artificial reproductive technologies is not the aspect of reproductive control that is most vital to their flourishing. Rather, access to birth control, safe abortion, antenatal care, and the like are more urgent needs, not to mention from the perspective of allocating scarce resources - cheaper ways to provide important benefits.

To sum up, there is a presumption in favor of permitting people to use new reproductive practices and technologies. Moreover, people's interests in procreation matter from the point of view of distributive justice. However, in our nonideal world, there are likely to be higher priorities for spending money on reproductive autonomy. These priorities should not be forgotten, even though much of the debate in bioethics over procreation focuses on novel and often expensive reproductive technologies.

\section{I0.3 Evaluating Creation}

We have defended a negative right to procreative autonomy. However, that right is limited by actions that wrong others. The main effects of procreative decisions concern the children who might be brought into the world. In this section we analyze possible wrongs to them under the labels of fixed-identity decisions and identity-determining decisions. Recall that fixed-identity decisions about procreation occur when someone chooses whether or not to bring a specific individual into the (postnatal) world. Can it be permissible to kill a fetus? Is it permissible to destroy an embryo created in vitro or to allow it to die? Identity-determining decisions occur when an agent's actions affect which individual will come into existence. Can such decisions be wrongful, even if the individual created was not harmed?

\section{Fixed-Identity Decisions}

Questions about whether it is permissible to damage or destroy individual human zygotes, embryos, and fetuses arise with regard to an array of ethical and policy issues. The most salient of these concerns the 
permissibility of terminating a pregnancy. But whether, when, and for what reasons women and girls should be permitted to utilize abortion services - or have them subsidized - is only one important issue. ${ }^{25}$ Consider, for example, embryonic stem-cell research (an issue we discuss in Chapter 7). This research is potentially very valuable, but it involves the destruction of human embryos. Or consider couples who use IVF and freeze embryos that are not ultimately implanted. Is it ethically permissible for couples or fertility clinics to discard the unused embryos? ${ }^{26}$

The most plausible reason for thinking that it is generally wrong to kill a fetus is that killing the fetus harms a being with moral status. ${ }^{27}$ As discussed in Chapter 7, if an individual has moral status, this means that others have obligations regarding their treatment of her that are based on her interests. In Chapter 7, we argued that only beings who are sentient at some point in time have interests and therefore moral status. A fetus that dies early in pregnancy - before the point at which it could be sentient will never be sentient and so, on our account, lacks moral status. Our account of moral status makes the permissibility of aborting pre-sentient fetuses a relatively straightforward matter.

Suppose, though, that someone doubted this view of moral status and claimed that the fact that the fetus would very likely become sentient if allowed to develop normally is sufficient for moral status. They would say the potential of the fetus was sufficient for moral status. For surplus embryos from IVF this might not matter - unless adopted for gestation, they would not otherwise develop into sentient beings. However, for a fetus that is currently being gestated it would. At least after the first few weeks of gestation (when rates of spontaneous abortion are high) the development of that fetus may be expected to proceed unless some intervention ends it.

Nevertheless, we think that even this more expansive view of moral status would not imply that killing pre-sentient fetuses is wrongful. This is because prior to sentience a fetus is not harmed by death; that is, the presentient fetus does not have an interest in continued life. In Chapter 4, we

25 We recognize that a trans male or gender nonconforming person might become pregnant and our conclusions in this section would apply to those persons too. We generally talk of women (or women and girls) in this context because of the heavily gendered nature of many discussions and policy decisions.

26 Ellen McCarthy, "Fertility Treatments Give Birth to Dilemma for Parents," The Guardian, May 23, 2015 (available at www.theguardian.com/science/201 $5 / \mathrm{may} / 23 /$ fertility-technology-unusedsperm-eggs).

27 For convenience, we use the term "fetus" to refer to all stages of human prenatal development. 
defended a gradualist view of what makes death bad for an individual. We argued that death is bad in virtue of what it deprives the decedent of, but in order for an individual to be deprived of future goods by dying, there needs to be some psychological connection between her present state and the goods that are lost.

No matter what we might think about the moral status of the fetus, it is clear that there are no psychological connections between the pre-sentient fetus and its future self. There are no such connections because the fetus does not yet have psychological states. Non-sentient fetuses are not psychologically connected to the goods of which death deprives them. Hence, we believe, they are not harmed by death. ${ }^{28}$ Nor would killing a presentient fetus violate the fetus's rights. In Chapter 7 , we argued that a creature must be more cognitively complex than merely being sentient having at least some nontrivial temporal self-awareness - in order to have rights. It follows that pre-sentient fetuses do not have rights.

Turn now to sentient fetuses. Sentience, at least in the form of the ability to feel pain, probably appears around twenty-eight weeks gestational age. ${ }^{29}$ It is at least possible that a fetus becomes sentient some weeks before then. ${ }^{30}$ Given our current understanding of the physiology underlying pain, however, it is not possible that sentience begins earlier than twenty weeks gestational age. ${ }^{3 \mathrm{I}}$

Since they are not yet persons (and if they die will not develop into persons) in the sense we describe in Chapter 7 , even sentient fetuses lack rights. Abortion therefore does not violate a right to life. But sentient fetuses do have interests that matter morally. It would be wrong to gratuitously inflict pain on a third-trimester fetus, for example. Would it be wrong to kill such a fetus? Clearly, killing a fetus that would develop into a person typically deprives it of a great deal of valuable life. However, the psychological links between the current fetus and its future life are very weak. It cannot matter much, if at all, to the fetus whether it misses out on

${ }^{28}$ For a more extended argument along similar lines, see David DeGrazia, Creation Ethics (New York: Oxford University Press, 20I2), 34-35. DeGrazia's argument shows a central problem for Don Marquis's celebrated argument against abortion ("Why Abortion Is Immoral," Journal of Philosophy 86 [I989]: I 83-202). In brief, Marquis argues that killing a person is wrongful because it deprives one of a valuable future. Since fetuses that are allowed to develop normally have a similar future - a "future like ours" - it is likewise wrong to kill even a presentient fetus. The argument fails if we adopt a gradualist account of what makes death bad for an individual.

29 Susan Lee et al., "Fetal Pain: A Systematic Multidisciplinary Review of the Evidence," JAMA 294 (2005): 947-954.

30 E. C. Brugger, "The Problem of Fetal Pain and Abortion: Towards an Ethical Consensus for Appropriate Behavior," Kennedy Institute of Ethics Journal 22 (201 2): 263-387.

3 I See Lee et al., "Fetal Pain." 
this future life. Thus, even for a sentient fetus, death is nowhere near the harm that it is for an older child or a young adult.

The foregoing discussion has some clear implications for the ethics of abortion. Prior to twenty weeks gestational age fetuses are not harmed by death. Assuming that the only considerations a pregnant woman needs to take into account concern the interests of the fetus, it is not even pro tanto wrong to terminate a pregnancy at this stage. After twenty weeks, it is possible that the fetus is sentient and can be harmed by death. Abortion will then be justified only when there is a sufficient moral reason in favor of it. Since the likelihood of fetal sentience and possibly the strength of a fetus's psychological connections to its future increase over the course of development after twenty weeks of gestation, it is morally preferable to abort earlier rather than later where possible. The moral reasons given to justify an abortion need to be weightier the greater the gestational age beyond twenty weeks. ${ }^{32}$

What sorts of reasons might justify inflicting the harm of death on a sentient fetus? Mere convenience would not be enough. Late-stage abortions are not generally sought for reasons of convenience, though. ${ }^{33}$ Parenting a child is a life-changing and time-consuming project. Suppose a woman becomes pregnant, does not think that she could bear to give up a child for adoption, but believes that raising a child would interfere with other valuable life goals. This might be sufficient justification. Likewise, for fetuses who are expected to have severe congenital conditions requiring a lot of additional care, we think it plausible that the additional burden on parents would be sufficient to justify a third trimester abortion, even for people who otherwise would want to become parents. Unsurprisingly, we also judge that serious risks to the life or well-being of the mother would be sufficient to justify even a late abortion. ${ }^{34}$

Our discussion so far has focused on the individual decision of a woman deciding whether to terminate her pregnancy. However, it also has

32 Here we have ignored a second common line of argument in favor of the permissibility of abortion. That line of argument - made popular by Judith Jarvis Thomson - starts from the premise that persons have strong rights to decide what happens to their bodies, so a pregnant woman would have no duty to continue a pregnancy even if the fetus were already a person. See Thomson, "A Defense of Abortion," Philosophy \& Public Affairs I (I971): 47-66; and David Boonin, A Defense of Abortion (New York: Cambridge University Press, 2003). For critical assessment of this argument, see DeGrazia, Creation Ethics, 39-43.

33 For example, only I.4 percent of abortions carried out in England and Wales take place after nineteen weeks (Roger Ingham et al., "Reasons for Second Trimester Abortions in England and Wales," Reproductive Health Matters 16 [supp. 31] [2008]: I 8-29).

34 In this category we include the trauma of carrying to term a pregnancy resulting from rape. 
important implications for other actors, including clinicians and the state. We briefly describe some of them here, though space does not permit a full ethical analysis.

First, safe abortions require some interaction with clinicians, whether to prescribe abortifacient drugs or to carry out surgical procedures. Some clinicians who have strong views about the morality of abortion may not want to be involved in providing abortion services. They may even consider it wrongful to refer patients to other providers who would be willing to assist with abortions, since this would make them complicit in acts they believe to be wrong. There are ongoing debates in several countries about whether clinicians have the right to refuse to provide certain medical services and what governments should do in response to such conscientious objectors. ${ }^{35}$ On the other side, clinicians in countries with restrictive abortion laws face dilemmas about how to help patients who seek termination of pregnancy. Suppose that the law permits a second trimester abortion in case of a threat to the woman's health. Should a physician interpret this exception so loosely that they essentially allow abortion on demand, even though they knows that this is not the intended interpretation of the law?

Second, there is the issue of what legal limits, if any, states should impose on access to abortion services, and whether access to abortion should be subsidized by the public health system. In general, where an act does not harm or wrong anyone, there is a presumption in favor of allowing it. ${ }^{36}$ This implies that it should be permissible for someone to obtain an abortion for any reason up to at least twenty weeks gestational age. After that time, we acknowledged the possibility that the fetus could be harmed by death (and probably is harmed by death after twenty-eight weeks gestational age). This harm to the fetus provides the sort of reason that might ground legal restrictions. Consistent with this idea, there are restrictions on late abortions even in countries with quite liberal abortion laws. For example, in the United Kingdom, abortions after twenty-four weeks are permitted only if "necessary to prevent grave permanent injury to the physical or mental health of the pregnant woman," if continuation of pregnancy increases the risk of the woman's death, or if there is a "substantial risk" that the fetus will be severely disabled. ${ }^{37}$

35 See, e.g., Carolyn McLeod and Jocelyn Downie, "Let Conscience Be Their Guide? Conscientious Refusals in Health Care," Bioethics 28 (2014): ii-iv, and the various articles in this special issue.

${ }^{36}$ See Chapter 5's discussion of the harm principle. $\quad 37$ The Abortion Act I 967, Section I(I). 
Although our arguments do support an ethical difference between decisions to abort, say, a first-trimester fetus versus a third-trimester fetus, we are less sanguine about marking this difference through a legal prohibition. This is because of the range of reasons we think could justify terminating even a late-stage pregnancy. They include judgments about what burden bringing a pregnancy to term would place on the pregnant woman. It would be very hard for someone other than that woman to make these judgments reliably. This does not rule out alternative ways to treat later terminations as more weighty decisions, such as offering counseling services for individuals contemplating abortion or mandating a more comprehensive informed consent process.

Turn now to public subsidy of abortion services. Here we see no difference between how the public health system should treat abortion and how it should treat other forms of birth control and medical treatments for pregnant women. Providing access to safe termination of pregnancy - wherever the line is drawn for when that is permitted - promotes the well-being of women by giving them control over important aspects of their bodies, including promoting reproductive autonomy, preventing the risks of illegal abortions, and avoiding the negative effects on health and other aspects of well-being of bringing an unwanted pregnancy to term.

Finally, on the flip side, the harm to late-stage fetuses who die or are injured provides a further reason in favor of providing health care interventions that benefit the fetus. For example, it supports the provision of prenatal care to reduce the risk of stillbirth. ${ }^{38}$ According to our arguments, stillbirth is bad not only for the woman but also for the fetus. ${ }^{39}$

\section{Identity-Determining Decisions: The Nonidentity Problem}

Suppose that a couple is considering procreation in the midst of an infectious disease outbreak. The woman currently has the disease, which involves minimal symptoms for her but would cause any child she gestated to have a developmental disability involving mild cognitive impairment and episodic pain. In three months, the woman will have cleared the infection from her system. Any child conceived after that point could be expected not to have the disabling condition. Should the couple stop using

38 The World Health Organization (WHO) defines a stillbirth as "a baby born with no signs of life at or after 28 weeks' gestation” (www.who.int/maternal_child_adolescent/epidemiology/stillbirth/en/).

39 Alexander Heazell et al., "Stillbirths: Economic and Psychosocial Consequences," Lancet 387 (2016): 604-6I6. 
contraception now, as originally planned, or wait three months before attempting to conceive?

Many couples might choose to delay for their own sake. They might want to avoid the additional burdens involved in raising a child with developmental problems. Policy-makers might recommend delaying pregnancy for the sake of societal benefits, such as reduced burden on the health care system. This policy goal might support increased subsidies for contraception, for example. But even if the couple would be happy to parent a cognitively disabled child and had the resources to do so well, many people believe that it would be morally wrong to choose to conceive now instead of waiting. ${ }^{40}$ This moral judgment is puzzling.

The puzzle is this. If the couple would be doing something wrong by having a child with cognitive and pain-causing disabilities, whom would they wrong? Assume that the child with disabilities has a life that is nevertheless well worth living. It then seems odd to say that they would wrong that child. If they delayed pregnancy, then that child would not exist: if the couple conceived in three months, a different sperm would fuse with a different ovum and produce a different child. This is the nonidentity problem: there seems to be a wrongful action but there does not seem to be a victim of the wrong. (The term "nonidentity" is used because the individual who comes into existence with the developmental disability is not identical to - is not the same individual as - the individual who would have come into existence had the couple delayed pregnancy.)

The nonidentity problem arises whenever an agent makes a choice that affects which individuals come into existence where those who come into existence following one choice are expected to have lives that are significantly worse than the different individuals who would come into existence following a different choice. ${ }^{4 \mathrm{I}}$ It will arise, for example, if a woman receiving IVF decides to implant an embryo with a deleterious congenital condition rather than one without it. It also arises at the population level. For example, consider the effects of human activity on the climate. The massive emissions of greenhouse gases are rapidly changing the earth's climate. Without dramatic action to curtail emissions soon, large areas of

$4^{\circ}$ Compare the more idealized cases in Dan Brock, "The Non-identity Problem and Genetic Harms: The Case of Wrongful Handicaps," Bioethics 9 (1995): 269-275, at 270; and Derek Parfit, Reasons and Persons (Oxford: Clarendon, 1984), chap. I6.

${ }^{4 \mathrm{I}}$ This problem was first examined systematically in Parfit, Reasons and Persons, Part IV. For a good overview of strategies for addressing this problem, see M. A. Roberts, "The Nonidentity Problem," in Edward Zalta (ed.), Stanford Encyclopedia of Philosophy (Winter 2015 edition; available at https:// plato.stanford.edu/entries/nonidentity-problem/). 
the earth will become much more hostile to human and other life. ${ }^{42}$ The resulting large-scale migration, conflicts over water, and other negative impacts are likely to make the lives of people living in fifty or a hundred years much worse. If we do nothing, then it seems that we wrong future generations. They will - and probably should - blame us for failing to change our lifestyles to protect the climate. However, dramatically reducing emissions of greenhouse gases would involve many people changing their behavior. Small changes such as how they get to work (e.g., taking a bus rather than driving) may easily lead to significant changes (e.g., whom they meet and with whom they ultimately procreate). At the very least, behavioral changes associated with more environmentally responsible lifestyles would likely affect the timing of procreative actions. Even a small difference in when two people conceive is likely to change which sperm fertilizes the ovum. And this, plausibly, is sufficient to change the identity of the person who is conceived. But then it appears that making the changes needed to avoid catastrophic climate change will also, within a small number of generations, change which people come to exist. If these future generations will have lives worth living even given the damage to the climate, then how can they complain that we did them wrong? After all, without climate change, they would not exist at all. ${ }^{43}$

Note that nonidentity cases are not usually cases of "wrongful life." Wrongful life cases arise when procreative decisions lead predictably to someone's quality of life being so bad that, for their sake, they should not have been brought into existence at all. This might apply to a child with a congenital condition such as Tay-Sachs disease, which was expected to cause so much suffering that the bad in her life would outweigh the good. A woman might discover through testing early in pregnancy that she is carrying a fetus with Tay-Sachs. If she judged that she ought to terminate the pregnancy, we can make sense of this judgment on the basis of the interests of the future child. ${ }^{44}$ Not so for most nonidentity cases, where existing with some predictable disadvantage nevertheless involves a life well worth living, such as in cases involving Down syndrome. ${ }^{45}$

${ }^{42}$ Intergovernmental Panel on Climate Change, Global Warming of $1.5^{\circ} C$ (2018) (available at www.ipcc.ch).

${ }^{43}$ Cf. Parfit's depletion case (Reasons and Persons, chap. I6, sect. I23). $\quad{ }^{44}$ See Chapter 8.

45 For some discussion of "wrongful life" suits and the associated philosophical issues, see Joel Feinberg, "Wrongful Life and the Counterfactual Element in Harming," Social Philosophy and Policy 4 (I986): I45-I78; and Seana Shiffrin, "Wrongful Life, Procreative Responsibility, and the Significance of Harm," Legal Theory 5 (I999): I I7-I48. 
The nonidentity problem has spawned a large philosophical literature. Here, we sketch some of the main ways in which philosophers have attempted to amend their moral theories to address the nonidentity problem. ${ }^{46}$ We then describe one proposed solution that we find promising and sketch its implications for bioethics.

The nonidentity problem arises out of three plausible but conflicting moral judgments. First, there are no victimless wrongs: if an action is wrong, then there must be some individual who is wronged. Second, if the only way that someone could come to exist involves their having some sort of welfare-reducing feature, they are not wronged by being brought into existence (provided that their life is worth living). The child whose parents could not have created her without a congenital condition causing chronic pain is not wronged by being born, provided that her life is worth living overall. Third, the acts described in the nonidentity cases we outlined are wrongful acts.

One solution to the problem is to deny that there are no victimless wrongs. On one version of this solution, we should adopt an "impersonal" morality, such as a utilitarian theory that requires agents to maximize the amount of well-being in the world, independent of who exists. This sort of view can explain very well why the couple should delay attempting to get pregnant and why people living now should take dramatic actions to reduce climate change. In both cases, the total well-being in the world will probably be greater.

Adopting an impersonal morality would solve the nonidentity problem. However, impersonal moralities tend to entail other moral judgments that are at least as implausible as the ones that they help us avoid. For example, it is widely held that killing another person is very wrong in most cases. It would be very wrong for a couple to kill an innocent, healthy twenty-yearold waiting in the bus line. It is also widely held that a decision not to procreate is not wrong in most cases. It would not be wrong for the couple to use contraception to avoid having a baby, even if their baby would likely have a flourishing life. But on a wholly impersonal morality, the act of removing a flourishing life from the world is, all else equal, no worse than the act of omitting to add a flourishing life. The utilitarian view that requires agents to maximize total well-being - an impersonal morality will regard the two acts as equivalent if their effect on well-being is the same. This seems clearly mistaken. Further, the reason it is mistaken seems

${ }^{46}$ Space precludes a comprehensive overview here. For longer discussions on which we draw here, see DeGrazia, Creation Ethics, I76-I 86; and Roberts, "The Nonidentity Problem." 
to be that the murder would violate the rights of the twenty-year-old and deprive him of a valuable future, whereas not procreating would not affect any actual person. Intuitions that what makes certain acts wrong is their effects on specific victims are strongly held.

A compromise would be to adopt a mixed view, such that there can be acts that are wrong because they affect specific individuals and acts that are wrong just in virtue of their impersonal effects. ${ }^{47}$ Such a view could explain the wrong in nonidentity cases because it would still be wrong, at least in some situations, to act in ways that produce worse outcomes, even when there is no victim of the wrongdoing.

The challenge for mixed views is to say exactly how impersonal effects matter. If a mixed view says that impersonal effects are just as important as personal effects, then it is likely to face similar problems to the ones facing wholly impersonal views. If impersonal effects matter less than personal effects, then some of those problems are reduced. Such a view could say that while it is good to create a child who will live a flourishing life, it is morally much more important to avoid harming a person who already exists. However, taking this route has its own challenges. There will be situations where the negative outcomes of two actions are similar but one affects who will come to exist and one does not. On a mixed view like the one we are considering, the identity-determining action should be taken, because its negative effects will not be as wrongful. So, for example, if we had the choice, it would be better to pollute the environment in ways that affect who comes to exist rather than in ways that do not, even when the outcomes for those who come to exist are the same. The Zika virus case we describe in Section I0.5 has this structure. We offer one possible way to address this challenge there.

A third response to the nonidentity problem is to bite the bullet and reject the judgment that there is any wrong done in nonidentity cases. ${ }^{48}$ All wrongs do indeed need a victim, and we do not need to cite mysterious impersonal effects or duties to maximize the amount of well-being in the universe. Our intuitive responses to the cases, one might argue, simply reflect the fact that we have trouble keeping in mind the difference in identity between the individuals who could exist. In cases where a couple could create a child now who could not exist without a condition that somewhat reduced her welfare, procreating does not wrong the child.

47 Cf. DeGrazia, Creation Ethics, I 84-185.

$4^{8}$ David Boonin, The Nonidentity Problem and the Ethics of Future People (Oxford: Oxford University Press, 2014). 
Since, on this view, there is no moral requirement to increase the total well-being in the universe, there is still no wrong done if the couple could have created a completely different child who would predictably fare better.

The greatest challenge for this bullet-biting response is how to deal with the effects of our actions on future generations. As described above, the many small actions that would be taken by people who currently exist in order to avoid the worst effects of human-made climate change will likely affect which people come into existence in future generations. It seems highly implausible that this means continuing to degrade and pollute the environment will not wrong them.

Our preferred solution to the nonidentity problem bites the bullet on a subset of nonidentity cases while arguing that other cases are not true nonidentity cases because there are victims. In addition, we think it is plausible that impersonal effects matter morally, though to a substantially lesser degree than do effects that impact specific individuals. A world with less suffering is morally better than a world with more suffering, all else being equal. And the fact that one state of affairs is morally better than another gives moral agents a reason to choose it. However, this reason is relatively weak when there is no victim or beneficiary of an agent's choice.

Our solution draws on ideas developed by Melinda Roberts. ${ }^{49}$ Roberts distinguishes two types of nonidentity case: genetic and expectational. In genetic cases, "the agent had, prior to conception, no ability whatsoever to make things better for the child than they in fact are." 50 The delayed conception case is a genetic case: there is no way for the couple to create this child without the increased risk of developmental disability. ${ }^{5 \mathrm{I}} \mathrm{By}$ contrast, in the expectational form of the nonidentity problem, "the agent has some slight chance - some slight expectation - of making things better for at least some future person." ${ }^{2}$ The climate change case is an example of this: for any individual living Ioo years in the future on an inhospitable planet it is very unlikely that she would have existed if humans had not polluted the planet as they did. Very unlikely, but not impossible, since nothing about polluting versus not polluting rules out the possibility that a particular future egg and sperm will join in either case.

\footnotetext{
49 For a clear statement of her view, see Melinda Roberts and David Wasserman, "Dividing and Conquering the Nonidentity Problem," in S. Matthew Liao and Collin O'Neil (eds.), Current Controversies in Bioethics (New York: Routledge, 2017), 8I-98.

50 Ibid., 83. $\quad 5$ I Note that Roberts uses the term "genetic" to refer to origins, not to genes.

52 Roberts and Wasserman, "Dividing and Conquering the Nonidentity Problem," 83.
} 
In genetic cases, Roberts believes that voluntarily creating a person who will have a flawed but worthwhile existence and whom the agent could not have created without the flaw need not be wrongful. We agree. Provided that third parties are not harmed or unduly burdened, then other members of society have no cause for complaint. And provided that the agent had some nontrivial reason for creating someone who has lower expected wellbeing than someone else she could have created, this can justify not making the world as good as she could have. As just noted, while we think that impersonal effects do matter, these impersonal effects do not have substantial moral weight.

To illustrate, return to the couple deciding whether to delay conception in order to avoid having a child with a developmental disability. Suppose that it would take a year for the woman to clear the infection and that women in her family have a history of early menopause - she is concerned that in a year's time she may be unable to conceive. This, it seems to us, would be sufficient reason to justify not delaying: they would not be introducing avoidable suffering to the world for a trivial reason.

On the other hand, suppose instead that the couple decide not to delay simply because they do not want to take an additional trip to pick up contraception. This would seem to fail to take seriously enough the challenges that a child born with a serious condition would experience. We could therefore criticize the couple for not taking into account the impersonal effects of their actions, such as the amount of well-being or suffering that they cause. Not delaying conception out of laziness would lead to a world with less expected well-being for no good reason. ${ }^{53}$

It does not seem overly counterintuitive to us that caring parents who accept having a child with a welfare-reducing disability do not act wrongly by bringing her into existence. Cases involving future generations are a different matter. It seems bizarre to think that future generations who have to struggle with the effects of climate change will not have been wronged by our twenty-first century neglect. Here, Roberts's distinction between the genetic and expectational forms of the nonidentity problems is crucial.

Consider one individual, Ahmed, living a life worth living oo years from now on an Earth damaged by irresponsible earlier choices regarding the climate. Should he wish that we had not made such choices because then he would be living a better life? Presumably not: the chances that

53 David Wasserman contends that the attitude of would-be parents toward their future child is also relevant to this assessment ("The Nonidentity Problem, Disability, and the Role Morality of Prospective Parents," Ethics I 6 [2005]: 132-1 52). 
Ahmed would have been born in the alternative timeline in which we reversed our irresponsible habits are very small indeed. This is why it might seem odd to say that Ahmed is harmed by the effects of our earlier choices.

But now consider the same question from the perspective of agents in the present. Suppose we are deciding whether to dramatically reduce emissions of greenhouse gases a century before the age of Ahmed. (It is, of course, implausible that we could collectively make a single choice of this kind, but imagining this possibility helps to simplify the thought experiment without affecting the moral lesson.) What are the chances that Ahmed, or any other specific possible individual, will exist in Ioo years? They are very small in both possible futures. But, as far as we know, he might exist in either. Which future should we prefer for possible person Ahmed? Presumably, we should prefer the future in which he exists in a more hospitable world to the future in which he exists in a much less hospitable world. Both are unlikely - as far as we know they are equally unlikely - but Ahmed is much worse off in one than in the other. ${ }^{54}$ His expected well-being is therefore lower under one choice than the other. This, we contend, provides the comparison that allows us to say that Ahmed is wronged if we make the irresponsible choice and he comes to exist. Ahmed, of course, is not special in this regard. For any possible person whose existence is - as far as we know - equally likely at the point of choosing whether to pollute, we can compare their lives in a polluting and a nonpolluting future. Each time, the expected well-being of that person is lower in the polluting future. Thus, whoever comes to exist on a polluting planet will be in a position to complain that they were wronged by our earlier actions.

To summarize, some procreative or other types of choices are identitydetermining, in that there was no way the agent could have created a person without that person suffering from some well-being-diminishing condition. Even though they could have created someone else with higher well-being, they generally will not have acted wrongly, provided that their procreative decision was not arbitrary or based on trivial reasons. In other cases, which initially appeared equally identity-determining, the person suffering from diminished well-being actually might have existed otherwise and the action that caused the diminished well-being did not make that person's existence any more likely. In those cases, acting in the way that leads to diminished well-being wrongs the person who comes to exist.

54 See Roberts and Wasserman, "Dividing and Conquering the Nonidentity Problem," 89-9I, for a more extensive argument to this effect. 
We have now extended our bioethical theory to encompass the ethics of creating human beings. Some of the practical upshot of our theoretical work becomes apparent as we apply it to two areas of bioethical interest: sex selection and reproductive decisions in the face of the Zika virus.

\section{I0.4 Sex Selection}

Many couples who procreate care about the sex of their child. Some may fervently want to have a girl or to have a boy. We now have medical technologies that would allow them to make this happen. Prior to conception, sperm-sorting techniques can be used to increase the proportion of sperm carrying either $\mathrm{X}$ or $\mathrm{Y}$ chromosomes that are used in intrauterine insemination. ${ }^{55}$ Prior to implantation using IVF, it is possible to select only embryos of one sex or the other. Post-conception, it is now possible to detect the sex of a fetus after seven weeks gestational age using noninvasive prenatal testing. Once the sex has been ascertained, elective abortion could be used to screen against children of the undesired sex. ${ }^{56}$

There are different reasons for which procreators might want to select the sex of their offspring. Some of these are medical. For example, Duchenne muscular dystrophy (DMD) is an X-linked recessive genetic disorder that causes severe suffering and premature death in males. A woman who thought she was a carrier of the mutated gene might want to select for a female child in order to avoid having a boy who suffered from DMD. Most commentators agree that avoiding serious hereditary diseases is sufficient justification for sex-selective procedures. They disagree regarding cases in which prospective parents wish to select the sex of their child, but do not anticipate that a child of the undesired sex would have a serious sex-linked health condition. For example, in many countries a large proportion of people have preferences for families with at least one son and one daughter. ${ }^{57}$ In others, cultural preferences for sons are so strong that the sex ratio has been dramatically skewed by sex-selective abortions,

55 Ethics Committee of the American Society for Reproductive Medicine, "Use of Reproductive Technology for Sex Selection for Nonmedical Reasons," Fertility and Sterility IO3 (2015): I4I 8-I 422 .

${ }^{56}$ In some countries, sex selection may also take the form of infanticide, either by directly killing (usually) female babies or through neglect. Since we regard these practices as obviously very wrong, we do not discuss them here.

57 See F. Arnold, "Gender Preferences for Children," Demographic and Health Surveys Comparative Studies 23 (I997): I-56; and Karsten Hank and Hans-Peter Kohler, "Gender Preferences for Children in Europe: Empirical Results from I7 FFS Countries," Demographic Research 2 (2000; available at www.jstor.org/stable/26347999). 
infanticide, and the mistreatment or neglect of female children. At birth, the natural ratio of male to female children is approximately I05:100. ${ }^{58} \mathrm{In}$ China, in 2017 it was estimated to be II 5:100. ${ }^{59}$ Similarly skewed sex ratios are found in many Indian states, countries in central Asia, and (until recently) South Korea. ${ }^{60}$

Regulations regarding sex selection tend to distinguish "medical" from "social" reasons. A 2009 analysis identified thirty-six countries with laws or policies on sex selection. Five of them, including South Korea, prohibited sex selection for any reason, and thirty-one, including China and India, prohibited it for "social" or "nonmedical" reasons. ${ }^{6 \mathrm{I}}$ Are such restrictions ethically justified? And would someone who used medical technologies to increase the chances of conceiving a child of a specific sex be acting wrongly?

Earlier in this chapter we argued for a general presumption in favor of permitting people to use reproductive technologies - the negative right to procreative autonomy. Restrictions on this liberty require justification. Absent such justification, individuals should be permitted to avail themselves of methods for choosing the sex of their child whether for medical reasons or because of their personal preferences. ${ }^{62}$

One possible justification for restricting sex-selective procedures is that sex selection would harm or otherwise wrong the child. ${ }^{63}$ It has been suggested, for example, that the flow cytometry method of sperm sorting might pose safety risks. ${ }^{64}$ The challenge for such justifications is that they seem to run afoul of the nonidentity problem. Sperm sorting affects which child comes into existence, and so it is hard to see how that child has been

${ }^{8}$ Fengqing Chao et al., "Systematic Assessment of the Sex Ratio at Birth for All Countries and Estimation of National Imbalances and Regional Reference Levels," Proceedings of the National Academy of Sciences I I6 (2019): 9303-93 II.

59 World Economic Forum, The Global Gender Gap Report 2018 (available at www.weforum.org/ reports).

6o Woojin Chung and Monica Das Gupta, "Why Is Son Preference Declining in South Korea?" (World Bank Policy Research Working Paper, 2007; available at https://ssrn.com/abstract= I02084I).

6I Marcy Darnovsky, "Countries with Laws or Policies on Sex Selection," Center for Genetics and Society (2009).

62 John Harris, "Sex Selection and Regulated Hatred," Journal of Medical Ethics 3 I (2005): 29I-294.

63 For discussion of other ethical objections raised against sex selection, see ESHRE Task Force on Ethics and Law 20, "Sex Selection for Non-medical Reasons," Human Reproduction 28 (2013): I 448-I454, at 20I3; Ruth Macklin, "The Ethics of Sex Selection and Family Balancing," Seminars in Reproductive Medicine 28 (2010): 31 5-321; David McCarthy, "Why Sex Selection Should Be Legal," Journal of Medical Ethics 27 (2001): 302-307; and Julian Savulescu and Edgar Dahl, "Sex Selection and Preimplantation Diagnosis: A Response to the Ethics Committee of the American Society of Reproductive Medicine," Human Reproduction I5 (2000): I879-I880.

64 ESHRE Task Force, "Sex Selection for Non-medical Reasons." 
harmed by the procedure given the reasonable presumption that they have a life worth living. Note that this same point applies to allowing sex selection on the basis of medical benefits to the child. When a female child is conceived instead of a male child in order to avoid an X-linked disorder, there is no individual who benefits by avoiding the disorder. Creating someone who will suffer less is better than creating someone who will suffer more, but we should not confuse this with saving any specific individual from suffering. Similar points about nonidentity have been raised to counter the view that sex selection should be prohibited because it constitutes sex discrimination. ${ }^{65}$ Someone might prefer a male or a female child for sexist reasons, but choosing the sex does not seem to discriminate against any actual individuals.

A distinct objection argues that would-be parents who opt for sex selection for nonmedical reasons violate a parental duty. Rosalind McDougall argues that because children's characteristics are unpredictable, virtuous parents would exhibit acceptance toward their child. ${ }^{66}$ A parent who would reject a child of the undesired sex fails to display this virtue, even if she in fact has a child of the sex she prefers. Similarly, Peter Herissone-Kelly argues that "proper parental love" is love that a parent would offer to "any incumbent" of the role of their child. ${ }^{67}$ Parents should not choose their children, since: "Under such circumstances, B's nature does not enjoy the independence from A's will that is a necessary condition of A's authentically loving him." ${ }^{68}$

Both arguments advance claims about the appropriate attitudes of parents. But both, we think, rely on dubious empirical assertions. McDougall claims that parents who attempt to have a child of one sex and end up with another will reject that child. However, in conception, as in other endeavors, trying for one outcome does not preclude acceptance of the actual result. Virtuous athletes try to win but accept it if they lose. Likewise, parents who try to raise their child to be sporty are still able to accept her when she prefers a book to a racquet. It seems perfectly possible that a parent could love any child they have while still trying to make the

${ }^{65}$ Macklin, "The Ethics of Sex Selection and Family Balancing," 317-3 I 8.

${ }^{66}$ Rosalind McDougall, "Acting Parentally: An Argument against Sex Selection," Journal of Medical Ethics 3 I (2005): 60I-605.

${ }^{67}$ See Peter Herissone-Kelly, "Parental Love and the Ethics of Sex Selection," Cambridge Quarterly of Healthcare Ethics I6 (2007): 326-335; and Peter Herissone-Kelly, "The 'Parental Love' Objection to Nonmedical Sex Selection: Deepening the Argument," Cambridge Quarterly of Healthcare Ethics I6 (2007): 446-455.

${ }^{68}$ Herissone-Kelly, "Parental Love and the Ethics of Sex Selection," 334. 
actual incumbent fit their preferences. We can, for example, make clear sense of the person who says, "I'm going to bring my son up to be sporty and assertive: it would be so painful to love a child who was weak and got bullied." And we do not regard adoptive parents who chose a child similar to them in race, of a specific sex, or with (or without) a disability as somehow disqualified from authentically loving their child.

At the individual level, then, there do not seem to be good reasons to prohibit sex selection. Two questions remain. First, should public resources be used to provide people with the means to select the sex of their child? In most cases, we think the claim to assistance will be weak when would-be parents are acting on personal preferences for the sex of their child - a case would have to be made for why this sort of preference could ground a claim to scarce health care funds. On the other hand, when sex selection would reduce the chances of creating a child with a serious health condition, there are good reasons for public resources to be spent on it. After all, it is those same public resources that will be used to treat the health condition, and reducing the amount of suffering in the world is a morally valuable goal.

The second question is how policy-makers should take into account the wider social effects of permitting or restricting the use of sex-selective technologies. Here we think much depends on the specific social context. There likely can be situations in which harm to others is sufficient to outweigh the value of procreative autonomy. For example, in countries where the sex ratio is heavily skewed, there are concerns about the social unrest that may result from the millions of men who will remain unmarried (given the value placed on marrying and having children). ${ }^{69}$ There might therefore be good reasons to restrict access to sex-selective technologies in these countries. Such considerations would not support restrictions in other countries, like most European countries, in which current sex preferences do not seem likely to skew the sex ratio.

\subsection{Zika and the Nonidentity Problem}

During 2015 and 2016 a Zika virus epidemic spread across Latin America and the Caribbean. Zika virus had previously been documented in only a few cases and was not considered a serious disease. It causes mild fever, joint pain, and rashes in about 20 percent of people infected. Zika virus is primarily transmitted by mosquito bites (though sexual transmission also

69 Xinran Xue, "The Worldwide War on Baby Girls," The Economist (March 4, 2010): 77-80. 
occurs). The warm temperatures and high rainfall of 2015 and 2016 were conducive to the spread of the virus, and tens of thousands of people were infected in Brazil and other South American countries. With the higher numbers of people infected, additional health effects of infection became apparent. In adults, a small fraction of people developed Guillain-Barré syndrome - a serious neurological disorder in which the body's immune system attacks the peripheral nervous system, sometimes causing extensive paralysis. Zika infection also affected some of the babies of infected pregnant women, causing congenital Zika syndrome (CZS) - a serious condition characterized by brain malformations, including microcephaly (small head size as a result of improper brain development). ${ }^{70}$

Due to the increased risk of microcephaly and other effects on fetal development, several countries recommended that women who were planning to become pregnant delay doing so. ${ }^{71}$ Outbreaks were expected to be limited in duration and people who became infected would likely develop immunity to the virus. Thus, delaying pregnancy by even a few months would substantially reduce the probability of giving birth to a child with CZS. These recommendations were criticized on the grounds that they placed responsibility for avoiding Zika infection on women living in countries where access to contraception was limited and more than 50 percent of pregnancies were unplanned..$^{72}$ But even for women with access to birth control and effective control over their reproductive lives, the recommendations generate an ethical conundrum by implicating the nonidentity problem.

In fact, this situation is very similar to the scenario we described in introducing the nonidentity problem. If a couple delayed conceiving during an outbreak, then they would reduce the probability that any child they created would have CZS. But, as we have seen, this would be a different child than the one they would have created during the outbreak. Any child born with CZS could not have been helped by such a delay.

The added complication in this case is that other measures could be taken to protect a fetus from the Zika virus. For example, mosquito control measures - such as indoor residual spraying, removal of breeding

70 World Health Organization, "One Year into the Zika Outbreak: How an Obscure Disease Became a Global Health Emergency" (Geneva: WHO, May 5, 2016) (available at www.who.int/ emergencies/zika-virus/articles/one-year-outbreak/en/).

${ }^{71}$ BBC News, "Zika Virus Triggers Pregnancy Delay Calls" (January 23, 2016) (available at www.bbc.com/news/world-latin-america-35388842).

72 Charlotte Alter, "Why Latin American Women Can't Follow the Zika Advice to Avoid Pregnancy," Time (January 28, 2016) (available at https://time.com/4197318/). 
sites, and individual use of insect repellants - would reduce the chances of a pregnant woman getting infected with Zika virus to begin with. Though there are no current vaccines or treatments available, research into Zika virus is underway, and such medical interventions may become available in the future. Individuals and governments have - or may have in the near future - methods to protect children who will come to exist.

Two types of decision-maker can be helpfully distinguished for the purposes of ethical analysis: individuals who are considering having a child and policy-makers deciding how to address a public health problem.

From the point of view of an individual woman or couple, our view on the nonidentity problem applies in a straightforward manner. All else being equal, they should choose to delay rather than conceive, since that will lead to the creation of a child with higher expected well-being. However, as we noted in our discussion above, all else may not be equal. If the couple have a nontrivial reason to press on with trying to conceive, then that may be sufficient to justify doing so. They cannot wrong the child they create by choosing to procreate now rather than later. Either way, means permitting, they should take steps to reduce risks to the fetus they actually conceive.

From the point of view of a policy-maker, matters are different. Resources for health care and public health are limited, so hard allocation decisions must be made. Resources spent on providing and promoting contraception cannot be spent on eliminating mosquito breeding sites and spraying insecticides. Does the nonidentity problem affect such allocation decisions?

To see why it might, consider two possible public health interventions. ${ }^{73}$ In the first, the government allocates its Zika funds to mosquito control measures. Where effective, these protect pregnant women and thereby fetuses who would otherwise have developed CZS. In the second intervention, the government allocates the same funds to providing at-risk individuals with contraception. Where effective, this delays conception and leads to the creation of individuals who do not have CZS instead of the creation of individuals who do have CZS. Suppose, for the sake of discussion, that the cost and impact on the number of cases of CZS are the same for each intervention. ${ }^{74}$ If the government should care more about

73 This scenario is based on one discussed in Keyur Doolabh et al., "Zika, Contraception, and the Non-identity Problem," Developing World Bioethics I7 (2017): I73-204.

74 If they differed, we would still want to know the cost-effectiveness of each and so we would still want to know if we should evaluate one differently than the other on the basis of nonidentity concerns. 
helping individuals who will exist than about "helpfully" changing which individuals will come to exist, then it should prefer the mosquito control measures. Indeed, even if the mosquito control measures are (somewhat) more expensive or less effective, this view would still imply that the government should prefer those measures.

Despite our views on the individual case, when it comes to the policy matter of allocating societal resources, we think that policy-makers should evaluate the two interventions in the same way. This is because the claims that individuals will have on societal resources are the same in both scenarios. Take a fetus that would develop CZS without the mosquito control intervention. The loss of well-being to the child into whom the fetus will develop grounds a claim to resources to prevent that loss. Equally, for those children who do get CZS, they will have a claim to resources to help treat their condition. The basis for the claim is the same, even though, given existing technologies, preventing CZS is much more cost-effective than treating its effects. Now consider a child born with CZS because her parents did not have access to contraception and so could not delay conception. That child will have the same claim to societal resources to treat her condition. In this case, the government could avoid having to expend scarce resources on treatment by preventing children who need treatment from coming into existence - that is, by providing access to contraception. From the point of view of a government deciding how to allocate scarce societal resources, the two interventions can be treated the same. 